\title{
Evolution of Information Technology Communication: How WeChat Become Indonesian Students Favorite Using Daily in China
}

\author{
$1^{\text {st* }}$ Dani Fadillah \\ Departement of Communication \\ Science \\ University of Ahmad Dahlan \\ Yogyakarta, Indonesia \\ dani.fadillah@comm.uad.ac.id \\ $4^{\text {th }}$ Fajar Dwi Putra \\ Departement of Communication \\ Science \\ University of Ahmad Dahlan \\ Yogyakarta, Indonesia \\ fajar.dwiputra@comm.uad.ac.id
}

\author{
$2^{\text {nd }} M$. Najih Farihanto \\ Departement of Communication \\ Science \\ University of Ahmad Dahlan \\ Yogyakarta, Indonesia \\ najiholic@gmail.com \\ $5^{\text {th }}$ Uspal Jandevi \\ School of Communication \& \\ Journalism \\ Nanjing Normal University \\ Nanjing, China \\ 30185309@stu.njnu.edu.cn
}

\author{
$3^{\text {rd }}$ Choirul Fajri \\ Departement of Communication \\ Science \\ University of Ahmad Dahlan \\ Yogyakarta, Indonesia \\ choirul.fajri@comm.uad.ac.id
}

\begin{abstract}
This study aims to explain how technological development, in this case the WeChat application, is able to provide comfort for foreign students studying in the People's Republic of China. This research is a qualitative research, data obtained by conducting interviews with Indonesian students who are in China for study. This research concludes that WeChat is their favorite application because it is not limited to being a communication tool, but also as a transaction tool and other means that support the needs of daily life.
\end{abstract}

Keywords-Information Technology Communication, Wechat, Indonesian, Students, China

\section{INTRODUCTION}

Indonesian people are familiar with various social media applications for communication in everyday life, say since the activities of the cyber world are known by the Indonesian people we know applications such as Massanger Black Berry, WhatsApp, Telegram, Line, Wechat and so on. Some of these communication applications are eroded by the times and abandoned by its users, some still survive and try to improve themselves by adding certain features so that they are not abandoned by users.

In Indonesia the various features of cyber communication continue to refine and update services, but basically they are all the same namely only as providing communication services. The various applications have not been able to make themselves in a safe position in the sense that they cannot be abandoned by the users because they can be replaced by other applications that are considered more popular and interesting to use.

Whereas in China, starting from the time the country opened up and carried out a development revolution, including in its communications world, there was an application which until now was still replaced by other cyber communication media applications, the application was 微信 or we know him better WeChat. This application dominates the world of cyber communications in the country of Tongkok. Not only for local residents, even foreigners staying for some time need to access the WeChat application's cyber service.

According to the Official WeChat Official Accounts page, a WeChat Official Account Platform is "a cooperation and promotion service that can be used by individuals, governments, media organizations and business enterprises. Official accounts can promote their brands to billions of WeChat users through their WeChat channel, thus reducing propagation cost, raising brand popularity and building more influential brand images." [1]

WeChat isn't only a messaging platform, but a social powerhouse that connects not only friends and family, but also businesses to consumers. Dominating the app market, it is used as a social messaging app that has largely replaced work emails, but also as a platform for mobile payments, ecommerce, train bookings and blogs, as well as being host to a universe of other apps [2].

Likewise for Indonesian students who continue their studies in China, before arriving in China they are users of mainstream cyber communication applications in Indonesia such as WhatsApp and Line but when they arrive in China they are in a variety of activities one day cannot be separated from application access activities WeChat. In China itself, there are various other cyber communications service applications such as Waibo, and QQ, but WeChat is still the first choice that cannot be abandoned.

Therefore this report was prepared to present the views of Indonesian citizens in China on how their perceptions of using WeChat with its various features, hopefully can provide input on the evolution and revolution of the ITC in Indonesia. 


\section{BASIC OF THEORY}

Information and Communication Technology is a broad umbrella terminology that includes all technical equipment for processing and delivering information. ICT covers two aspects, namely information technology and communication technology. Information technology consists of all matters relating to the process, use as a tool, manipulation, and management of information. While communication technology is everything related to the use of tools to process and transfer data from one device to another. Therefore, information technology and communication technology are two inseparable concepts. So Information and Communication Technology contain a broad understanding that all activities related to processing, manipulation, management, transfer of information between media. The term ICT emerged after the combination of computer technology (both hardware and software) with communication technology in mid-century 20. The combination of the two techniques is developing rapidly beyond other fields of technology. Until the beginning of the 21 st century, ICTs continue to undergo various changes and have not seen a saturation point. [3].

The development of technology led to the communication revolution and influenced the development of society. Community activities are inseparable from the technology used since $\mathrm{BC}$ before entering the era of the digital millennium today. It is ranging from people who rely on simple technology using leaves, clay to write information messages to the public until the use of the most sophisticated technology today. Technology brings developments in society and is shown by changes that occur in political, economic, social, and cultural aspects. The political issue of information and communication technology is increasingly advanced to make the media controlled by particular interests, which then established the mass media industry and used it as an extension of political affairs. Not only that, if previously Marx mentioned the dominance of the bourgeoisie over the proletariat when it happened in the industrial era where developing technology was still limited to paper-based communication, now the power is no longer related to the source of model ownership, but rather to the instrumental reason of the rulers [4].

In the social sphere, technology brings changes in the way of communication in society, organizations/companies, and families. If previously, the importance of communicating directly was always used by the public in conveying information. Now, without face-to-face-to-face meetings, people can exchange information; parents can also control their children's whereabouts when using each other by using mobile phones or through video messages. Unfortunately, the ease of communication brings social relations that had become sticky because of technological inventions. People seem to disregard previous social values because they are considered inefficient with the current high level of community mobility. Technology also raises inequality in a society where the ownership of electronic devices then classifies specific communities into lower, middle or upper social groups [5].

Information and communication technology currently brings changes that affect society's economy. Especially people who have businesses, both small and medium scale, are now utilizing technology in marketing their products. For example, for BlackBerry users, perhaps they are familiar with the name Broadcast Message selling goods. Sent from one cellphone then copied to another cellphone in a network, then nowadays too many online shops are found either on Facebook, Twitter or Instagram which are considered to make it easy for entrepreneurs to save on advertising costs, especially for novice businessmen who have mediocre capital . If there are still people who make transactions directly to the shopping center, the payment system can not only be done with cash, but can also directly swipe with a particular machine that can be used by all debit and credit card users. [6]:

Once again, please remember that humans enter a new stage of society called the information society. The information society is a society that carries out significant distribution, use, and manipulation of information in Economic, Political, and Cultural activities. The aim is to gain an international competitive advantage through the use of Information Technology creatively and productively. The knowledge economy is a partner where wealth is created through the exploitation of an understanding of the Economy. People who have the means in the community are called Digital citizens [7].

Even in some parts of the world the community has turned into an information society. The term information society is often used to describe a culture and an economy that uses high-intensity information technology tools in everyday life. The community uses the same technology or compatible with various personal, social, educational, business, and even leisure activities. The technique can send, receive, and exchange digital data quickly between places regardless of distance. In the business sector, most financial transactions, such as those carried out by banks, have used information technology, such as internet banking services [e-banking], mobile banking, and others. Modern humans cannot be separated from information technology in carrying out daily activities, which are carried out through mailing lists, e-mails, and interacting with cyberspace communities. So it can be said that information processing is the core of modern human activities using new technology. This has implications on all aspects of people's lives and changes the way modern humans do various activities in the fields of Economy, Education, Health, and even in utilizing free time to consume and produce information [8]

The development of information technology causes human dependence on information technology is increasingly high. The public becomes information consumers and also produces information. The entire world community spends an average of about half of their lives in contact with information technology, both through uploading videos on YouTube, writing and responding to status on social media such as Facebook and Twitter, writing and responding to emails, and so on. So now humans work and play within the scope of the information society. Information technology continues to develop every generation. Conventional media combined with new media have changed the pattern of media consumption and people's lives. Almost everyone uses cellphones and emails to support their daily activities. Conventional media have entered into new media namely digital media and telecommunications networks that offer new lifestyles, create new jobs, and new social issues [9].

That is what causes social network users to increase because there are no hierarchical boundaries in 
communication. The social network society is growing due to the need to express ideas and human thoughts related to the Political, Economic, Social, and Cultural situations caused by the spread of networks and Digital technology. Social networks arise due to the influence of modernization, industrial capitalism, and the need for humans to carry out various activities quickly without space and time restrictions.

\section{RSEARCH METHOD}

This research model is qualitative research with a descriptive approach. This paper seeks to understand and find the meaning of an event, including the process of interaction and patterns of human behavior at certain times and situations. In conducting research, the author first identifies the problem by conducting a literature study from a variety of available sources, then conducting discussions with representatives of the Chinese Indonesian Student Association in the city of Nanjing, both the management to the council of supervisors, related to the object and subject of this research study.

\section{RESULT AND DISCUSSION}

The development of technology in China not only creates a comfortable ecosystem in the digital world but is also worth studying. Because WeChat used to be just a messaging application like Whatsapp. However, now WeChat has become a basic need of the digital community in China. WeChat, which was discovered in 2011, is owned by Tencent with 1 billion active users and around 38 billion messages mobilized through this platform. Last year, Tencent added the mini-apps feature on WeChat, brought up derivative applications on $\mathrm{WeChat}$ that allowed users to play games, pay bills, find friends in the neighborhood, order queues for doctors, report to the police, call a taxi, hold a video conference, and access bank services. This governmentsubsidized application also allows the Chinese community to communicate directly with the government because the government has an official account on WeChat. No doubt, the dominance of WeChat in China is also thanks to the interference of the government.

In addition to being loved by the public, WeChat is also preferred by providers of goods and services. Based on the information that the author successfully collected, providers of goods and services use WeChat to hook consumers; they create official accounts so they can interact directly with consumers. Consumers can add them to their network and get messages containing promos and discounts directly. The message contains a link that points to the product provider's page. Purchase of goods and services as well as payment can be made with just one application. In addition, advertising services are provided for providers of goods and services on WeChat which can be seen by the Chinese community. Not surprisingly, if then WeChat became the focus of developing digital ecosystems in China. Money transfer services, especially red emvelope (红包 read: hongbao) transfers during Chinese New Year, can also be done between WeChat users, who are also said to want Facebook to be copied.

WeChat's presence as a payment application can revolutionize China into a cashless society overnight. They can use the app to buy various goods and services, ranging from a handful of watermelons to flight tickets.

A very positive public response has a significant influence on the success of the two applications. Instead of protesting and complaining, the Chinese people welcome the arrival of this advanced technology because it makes their lives more comfortable and more efficient.

Amazingly, this new technology not only controls young people but also people in an older age range. Various layers of Chinese society, even to farmers who live in rural areas, have used WeChat for payment. One fact that may be very surprising is that beggars in China are starting to use WeChat for people who have a reason not to have the cash to give them.

The popularity of WeChat and Alipay as payment applications is indeed very high. There are hardly any Chinese people who don't use both of these applications. What are the advantages offered by the application to become very popular?

\section{1) Much more practical and comfortable}

The first reason, of course, is practicality and convenience in the transaction. Both applications are straightforward to use anywhere and anytime in China. You can make payments at malls, small shops, or even roadside stalls using WeChat. No need to bother, you scan the barcode, and the transaction is complete.

No need to wait for the seller to count your money, count the change, and give it to you. If you are a person who believes that time is money, small things like this can be a waste of time. The presence of payment applications in China, such as WeChatmakes things more convenient and comfortable, both for buyers and sellers.

\section{2) Reduce the risk of pickpockets}

Criminal acts such as pickpockets are still a problem in various countries, including China. The presence of a payment application creates a cashless society in China. This brings a positive impact on other aspects of life, namely reducing the risk of pickpocketing. The logic is simple; if you do not carry a wallet, then pickpocket will not be interested in aiming at you. In addition to reducing crime rates, it also alleviates anxiety and stress on someone who wants to make large amounts of transactions.

\section{3) No need to carry money anywhere}

Bringing money - especially coins - can be very troublesome. Imagine when you were queuing up in a restaurant in a long line, suddenly when paying your coins fell and scattered in all directions. Two things are very likely to happen: 1) You feel ashamed because you have to pick them up one by one, and 2) everyone will try to help you collect your coins, which can make you even more embarrassed. Of course, no one wants to experience the above incident. That is why Chinese people prefer to use payment applications for transactions. There is no need to carry money and wallets everywhere, and payments can be made in a short time.

\section{4) Lots of promo deals and coupons}

Payment applications that work with many merchants will often hold promos and offer coupons for users. This also happened to WeChat. All tickets and discounts are available as one in the application, so you don't have to bother figuring out which places are holding discounts or what coupons are being offered. Once again, this is about efficiency. Imagine how smooth a transaction would be if you could find discounts, coupons, and make payments at one time. 


\section{5) Complete expense report}

Keeping track of expenses is an essential thing in managing personal finances. But still, some people often skip the habit because they are too busy. Not to mention if the amount of expenditure does not match the remaining money owed. You will surely be dizzy thinking about where some of your money goes. But that won't happen if you use a payment application like WeChat. You can get complete reports - be it daily, weekly, or monthly - about all the transactions you make. You can access it easily anytime and anywhere, without the hassle of opening notes and carrying books everywhere. Elementary and practical, right?

\section{6) Company promotion}

One of the factors that determine success is the promotion carried out by the company. That has influenced the popularity of WeChat as payment applications in China. The companies are conducting socialization and development to the public so that they are all interested in using the app. To achieve change, many parties play a role and take part in it. The presence of new technology is welcomed by people who want to change. Keep in mind that it is not easy to change a tradition that exists in society. How China responds to the presence of new technology is necessary to be emulated by any community in the world.

\section{CONCLUSION}

WeChat, which can provide services that are more than just communication applications, has made it the most popular app for Indonesian students in China.

Collaboration with various financial institutions and other social services has been able to make Wecvhat an application that cannot be released from everyday human life. Besides that, WeChat also looks serious in cooperating with the security forces to improve the quality of its security, so that its users don't have to worry when using WeChat for various purposes.

\section{ACKNOWLEDGMENT}

Thank you to Indonesian students in China who are willing to be the resource persons in this research. Our gratitude also goes to the Jogja Communication Conference 2020 committee, who has agreed to pass this manuscript for publication.

\section{REFERENCES}

[1] X. Che and B. Ip, "WeChat," in Social Networks in China, 2018

[2] C. H. Lien and Y. Cao, "Examining WeChat users' motivations, trust, attitudes, and positive word-of-mouth: Evidence from China," Comput. Human Behav., 2014, doi: 10.1016/j.chb.2014.08.013.

[3] D. Fadillah, L. Zhenglin, and D. Hao, "Big Data and the Revolution of Political Campaign in Indonesia," in Proceedings of the 2019 Ahmad Dahlan International Conference Series on Education \& Learning, Social Science \& Humanities (ADICS-ELSSH 2019), 2019, doi: 10.2991/adics-elssh-19.2019.19.

[4] D. Fadillah, L. Zhenglin, and D. Hao, "Social Media and General Elections in Malaysia 2018 and Indonesia 2019," J. Komun. ISKI, vol. 4, no. 1, pp. 1-8, 2019, doi: 10.25008/jkiski.v4i1.255.

[5] F. F. Lotan, "Making a positive internet through Socmed Agawe Guyub," Int. J. Commun. Soc., vol. 1, no. 1, pp. 9-16, 2019, doi: 10.31763/ijcs.v1i1.22.

[6] D. L. Lester, J. A. Parnell, and S. Carraher, "ORGANIZATIONAL LIFE CYCLE: A FIVE-STAGE EMPIRICAL SCALE,” Int. J. Organ. Anal., 2003, doi: 10.1108/eb028979.

[7] U. Jandevi, "New media for increasing political participation in Indonesia," Int. J. Commun. Soc., vol. 1, no. 1, pp. 1-8, 2019, doi: 10.31763/ijcs.v1i1.19.

[8] Umarino, C. Fajri, and D. Fadillah, "CITRA PKU MUHAMMADIYAH YOGYAKARTA SEBAGAI RUMAH SAKIT ISLAM,” J. Interak., vol. 1, no. 2, pp. 128-141, 2017.

[9] M. Ulfah and A. Barry, "Indonesia Leader Forum, post-truth and political interests in social media and television," Int. J. Commun. Soc., vol. 1, no. 1, pp. 17-25, 2019, doi: 10.31763/ijcs.v1i1.18. 